\title{
Review
}

\section{Peri-prosthetic bone cysts after total ankle replacement. A systematic review and meta-analysis ${ }^{\text {ts }}$}

\author{
Joana Arcângelo ${ }^{\mathrm{a}, *}$, Francisco Guerra-Pinto ${ }^{\mathrm{b}}$, André Pinto $^{\mathrm{c}}$, André Grenho $^{\mathrm{a}}$, \\ Alfons Navarro ${ }^{\mathrm{d}}$, Xavier Martin Oliva ${ }^{\mathrm{e}}$ \\ a Orthopedic Surgery Department, Hospital Curry Cabral - Centro Hospitalar Lisboa Central, Lisboa, Portugal \\ ${ }^{\mathrm{b}}$ Orthopedic Surgery Department, Hospital de Cascais, Cascais, Portugal \\ c Orthopedic Surgery Department, Centro Hospitalar de Coimbra, Coimbra, Portugal \\ d Human Anatomy and Embryology Unit, School of Medicine, University of Barcelona, Spain \\ e Human anatomy Unit, School of Medicine, University of Barcelona, Foot and Ankle Unit, Clinica del Remei, Barcelona, Spain
}

\section{A R T I C L E I N F O}

\section{Article history:}

Received 23 July 2017

Received in revised form 1 November 2017

Accepted 15 November 2017

\section{Keywords:}

Cystic osteolysis

Peri-prosthetic osteolytic lesions

Bone cysts

Ankle arthroplasty

Total ankle replacement

\begin{abstract}
A B S T R A C T
Background: Periprosthetic cystic osteolysis is a well-known complication of total ankle replacement. Several theories have been proposed for its aetiology, based on individual biomechanical, radiological, histopathology and outcome studies.

Methods: Studies that met predefined inclusion/exclusion criteria were analysed to identify literature describing the presence of peri-prosthetic ankle cystic osteolysis. Quantitative data from the selected articles were combined and statistically tested in order to analyse possible relations between ankle periprosthetic bone cysts and specific implant characteristics.

Results: Twenty-one articles were elected, totalizing 2430 total ankle replacements, where 430 developed peri-prosthetic cystic osteolysis.

A statistically significant association $(P<.001)$ was found between the presence of bone cysts and nonanatomic implant configuration, hydroxyapatite-coating, mobile-bearing and non tibial-stemmed implants. No significant association existed between the type of constraining and the presence of cysts $(P>.05)$.

Conclusions: Non-anatomic, mobile-bearing, hydroxyapatite-coated and non tibial-stemmed total ankle replacements are positively associated with more periprosthetic bone cysts.
\end{abstract}

(C) 2017 European Foot and Ankle Society. Published by Elsevier Ltd. All rights reserved.

\section{Contents}

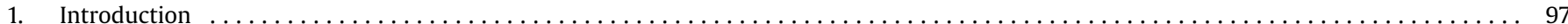

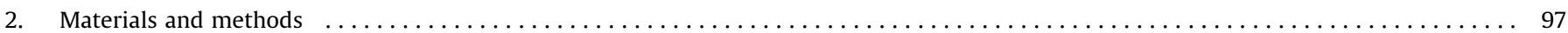

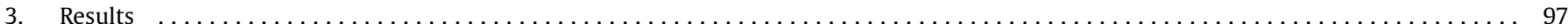

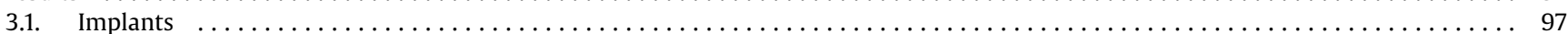

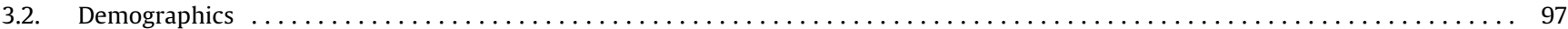

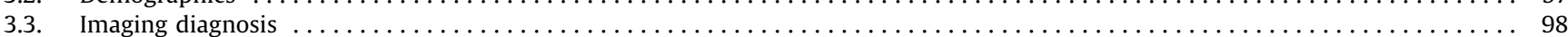

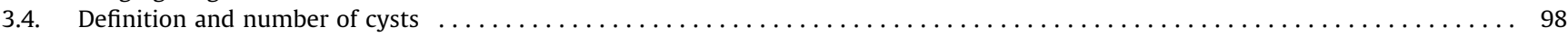

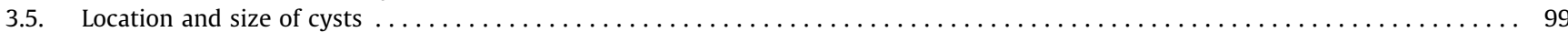

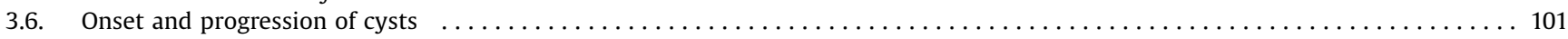

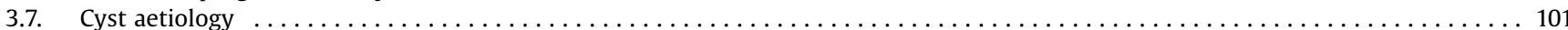

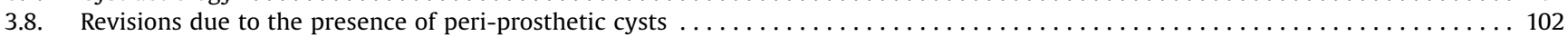

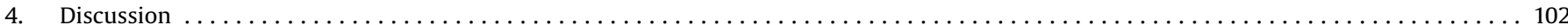

\footnotetext{
ts This research did not receive any specific grant from funding agencies in the public, commercial, or not-for-profit sectors.

* Corresponding author at: Hospital Curry Cabral - Centro Hospitalar Lisboa Central, R. Beneficência 8, 1050-099 Lisboa, Portugal.

E-mail addresses: joana.arcangelo@gmail.com (J. Arcângelo), fguerrapinto@gmail.com (F. Guerra-Pinto), andrepinto4796@hotmail.com (A. Pinto), andre.grenho@gmail.com (A. Grenho), anavarroponz@ub.edu (A. Navarro),xmoliva@inbox.com (X. Martin Oliva).
} 


\section{Introduction}

Total ankle replacement (TAR) is a promising alternative to arthrodesis in selected patients with end-stage ankle osteoarthritis $(\mathrm{OA})$, allowing for pain relief and articular range of motion preservation [1]. Nevertheless, retrospective studies show a high failure rate when compared with other joint replacements, such as total hip (THA) and total knee arthroplasties (TKA) [1,2]. Since its first report in 2004 [3], periprosthetic osteolysis has been recognized as an important risk factor for TAR failure. Several theories have been proposed to explain the underlying mechanisms of this phenomenon and the elevated rate and early onset of cysts in TARs, opposing to TKAs and THAs [4-6]. According to a recent review on the aetiology of TAR osteolysis, published by Espinosa et al. [7], variables such as age, body weight, activity lesions, implant designs, fixation methods, material properties, immunologic responses, biomechanical adaptations to total ankle replacement and even inherited aberrant cellular responses to particle wear, all contribute to the development of perioprosthetic osteolysis. Across the studies the main factor responsible for periprosthetic bone cyst formation is the inflammatory cytokinecascade response activated by wear debris particles, and its consequent osteoclast activity stimulation [7-11]. For instance, mechanical factors such as high joint fluid pressure and implant instability increase micro-motion and stress shielding, contributing to the production of wear debris [6]. Additionally, the inflammatory response to these particles depends on their biological type (polyethylene, metal and hydroxyapatite), shape, concentration and size $[7,9,12]$.

This study performs a systematic review and meta-analysis of all published articles that evaluated periprosthetic cysts after TAR, which consensually represent one of the main problems leading to implant failure and, consequently, to revision arthroplasty or conversion into an ankle arthrodesis. Most revision series were evaluated for survivorship of different TAR prosthesis models. No systematic revision, however, has yet specifically analysed the predisposing factors for periprosthetic cyst formation. Therefore, our main objective is to review implant design and material properties related risk factors for bone cyst formation and to statistically analyse the relation between these variables and the number of cysts described across the currently published studies. Additionally, we provide an overview on type and main implant characteristics, imaging diagnosis, cysts main characteristics (size, location, timing of detection, progression and histopathology results), revision surgery due to cysts, and current bone cyst etiologic theories, described along the publications reviewed.

\section{Materials and methods}

A comprehensive review of the literature was performed in January 2017 using the PubMed database and keywords "cyst"; "osteolysis" or "lucency" and "ankle arthroplasty"; "ankle replacement" or "ankle prosthesis", returning 73 articles (Fig. 1). The reference list of each pertinent article was screened for other relevant papers. Resulting abstracts were reviewed to identify literature that described the presence of peri-prosthetic ankle cystic osteolysis. Exclusion criteria were applied (Table 1) based on a previous systematic review on TAR outcome [13]. In studies which reported on the same cohort of patients at different followups (kin studies), we ensured that every patient appeared only once and included data from only one kin study. All abstracts were reviewed and assigned a classification (I-V) of Level of Evidence (LOI). Data extracted from each study included demographic data (age and gender), type and main implant(s) characteristics (type of coating; polyethylene; constraining; number of components and type of bearing), total number of patients and ankles treated, primary indication for total ankle replacement, imaging diagnosis methods used, time of follow-up, number of cases with cysts, cysts main characteristics (size; location; timing of detection; progression and histopathology results); number of revisions due to cysts, technique used in revision and stability of the implants during revision surgery. Implants were classified as non-anatomic or anatomic according to the shape of the talar implant with nonanatomic models having a spherical talar component $\left(\mathrm{STAR}^{\mathbb{R}}\right.$; AES $^{\mathbb{R}}$; Agility ${ }^{\mathbb{R}}$; Ramses ${ }^{\mathbb{R}}$ ) and anatomical implants (Hintegra ${ }^{\mathbb{R}}$; SALTO $^{\circledR}$; BOX ${ }^{\mathbb{R}}$; Salto Talaris ${ }^{\mathbb{}}$; INBONE ${ }^{\circledR}$ and Mobility ${ }^{\mathbb{R}}$ ) respecting the two talar curve radii. We further registered and analysed the aetiologies of ankle peri-prosthetic bone cysts as proposed by each author.

Implant characteristics were statistically analysed according to the number of cases with cysts encountered, using a 2-sided independent Student's t-test and a $\mathrm{X}^{2}$ analysis. Statistic analysis was performed using SPSS software. Statistically significant $P$ value was set as $P<.05$.

\section{Results}

Abstracts of 73 articles were reviewed and 11 papers were excluded for not being relevant to the topic, leaving 62 that were studied in detail. Ten additional studies were added after review of reference lists. Forty-two studies met the exclusion criteria, six were excluded because of cohort duplication and three mixed studies (comparing different implants) were excluded because there was no discrimination of the number of cysts for each type of implant, leaving 21 studies for analysis (Fig. 1), published from 2004 to 2016 [3,14-33]. Table 2 summarizes main author, year of publication, level of evidence, type and number of implants studied, demographic data, time of follow-up and number of cysts encountered for the 24 selected articles. Most studies were level IV retrospective case series (13 of $24,61.9 \%$ ). Level II and level III studies contributed to $9.5 \%$ ( 2 of 21 ) and $28.6 \%$ ( 6 of 21 ) of the studies, respectively.

\subsection{Implants}

Table 3 details the main characteristics and distribution of the implants studied in the selected articles. A total of 2430 ankles (2322 patients) were reviewed. Of the 10 different implants studied, the STAR ${ }^{\circledR}$ prosthesis (Small Bone Innovations Inc., Morrisville, Pennsylvania) had the greatest number of TARs $(n=499)$ in the literature reviewed and was mentioned in the highest number of publications $(n=8)$. In 19\% (4 of 21) of the publications one of the authors was the designer of at least one of the implants included in the study.

\subsection{Demographics}

A total of 15 papers discriminated patient gender, of which $50.9 \%$ (464 of 910 patients) were female and 49.1\% (446 of 910 patients) were male. The average age across the studies (not reported in 3 studies) ranged from 54 to 67.7 years old. The primary indication for TAR was given in 17 studies. Most common 


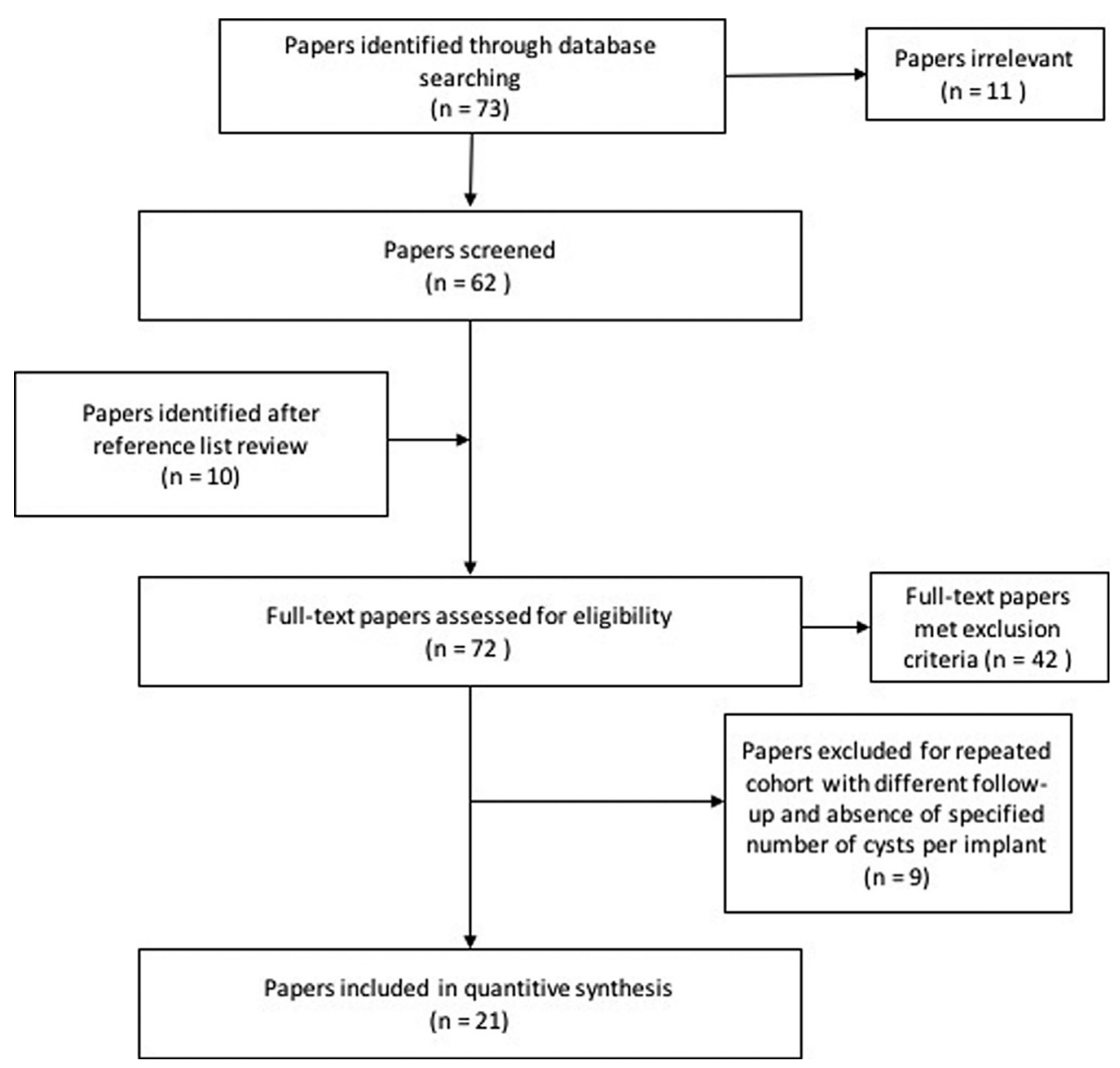

Fig. 1. PRISMA flow chart of the literature search.

indication (Fig. 2) was posttraumatic OA (42.8\%, 545 of 1274 ankles), followed by systemic arthritis (26.8\%, 342 of 1274 ankles), idiopathic OA (25.7\%, 328 of 1274 ankles) and OA secondary to instability (3.5\%, 44 of 1274 ankles). The average length of followup ranged from 2 to 12.4 years.

\subsection{Imaging diagnosis}

In $61.9 \%$ ( 13 of 21 ) of the studies X-ray was the only radiological method of osteolysis detection. One study compared diagnostic accuracy between weightbearing digital radiography and 3D weightbearing multiplanar reconstructed (MPR) fluoroscopic imaging, concluding that significantly more cysts were detected with 3DMPR (74 vs. 55, $P=.03$ ) [26]. One study [30], systematically performed X-ray and CT in all patients, comparing their diagnostic performance with a maximum follow-up of 5 years. CT scan depicted more cystic lesions than conventional radiograph, both in the tibia and the talus. Moreover, CT showed a significant trend towards more severe lesions. The authors also concluded that axial view is the best CT scan view to detect these lesions, specifically lesions in front or behind the tibial stem. In one study [25], CT was performed in every patient with at least one osteolytic lesion greater than $10 \mathrm{~mm}$ and in all patients that reached the last follow up. Similarly, CT performed better than conventional radiographs (CR) with the study reporting 98 major lesions (greater than $10 \mathrm{~mm}$ ) detected with CR versus 222 with CT. This difference was especially significant for the detection of talar lesions $(P<.0001)$. In Yoon et al. [27], conventional radiograph sensitivity to identify lesions of any size, compared to CT, was 53\% and only $50 \%$ for lesions under $100 \mathrm{~mm}^{2}$. Five additional studies [21,27,29,31,32], used CT non-systematically, usually only in the presence of positive radiographs and made no comparison between the two diagnostic methods.

\subsection{Definition and number of cysts}

A great variability regarding the definition of bone cystic lesions was found across the studies. "Cysts", "ballooning lysis", "large osteolytic cavity", "osteolysis greater than $2 \mathrm{~mm}$ ", "cavity", "cavitation", "subchondral cysts", "cystic-like osteolytic lesion",

Table 1

Exclusion criteria for search (TAR, total ankle replacement).

1 Papers that reported series of less than 20 TARs

2 Papers reporting on TARs with mean follow-up inferior to 2 years

3 Studies published in non-indexed journals

4 Reviews, case reports, and basic science articles

5 Papers with no mention of absolute or relative size of the lesions found

6 Papers reporting on lucency or radio-lucent lesions with $<2 \mathrm{~mm}$ and/or no mention of cystic/ballooning shape 
Table 2

Details of the 21 studies included in the present review.

\begin{tabular}{|c|c|c|c|c|c|c|c|c|c|c|}
\hline Author & Year & $\begin{array}{l}\text { Implant(s) ( } \mathrm{n} \text { if mixed } \\
\text { study) }\end{array}$ & $\begin{array}{l}\text { (Co) author = implant } \\
\text { designer }\end{array}$ & $\begin{array}{l}\text { Total of } \\
\text { ankles }\end{array}$ & $\begin{array}{l}\text { Total of } \\
\text { patients }\end{array}$ & M & $\mathrm{F}$ & $\begin{array}{l}\text { Mean } \\
\text { age }\end{array}$ & $\begin{array}{l}\text { Mean follow-up } \\
\text { (months) }\end{array}$ & $\begin{array}{l}\text { Cases with } \\
\text { cysts }\end{array}$ \\
\hline Knecht et al. & 2004 & Agility & Yes & 132 & 126 & NR & NR & 61 & 108.0 & 57 \\
\hline Kopp et al. & 2006 & Agility & No & 40 & 38 & 13 & 25 & 67.7 & 44.4 & 8 \\
\hline Schutte et al. & 2008 & STAR & No & 49 & 47 & 16 & 31 & 57.1 & 27.6 & 30 \\
\hline Wood et al. & 2010 & Mobility & Yes & 100 & 96 & 53 & 43 & 66 & 51.6 & 5 \\
\hline Bonnin et al. & 2011 & SALTO & Yes & 98 & 96 & 36 & 60 & 56 & 81.6 & 19 \\
\hline Kokkonen et al. & 2011 & AES & No & 38 & 37 & 12 & 25 & 54 & 28.0 & $\begin{array}{l}2 \\
7\end{array}$ \\
\hline Mann et al. & 2011 & STAR & No & 84 & 80 & NR & NR & 61.4 & 109.2 & 10 \\
\hline Wood et al. & 2013 & STAR & No & 62 & 60 & 29 & 31 & 57.3 & 38.4 & 1 \\
\hline Bianchi et al. & 2012 & BOX & No & 200 & 200 & & & & 46.0 & 5 \\
\hline Brunner et al. & 2013 & STAR & No & 77 & 72 & 35 & 37 & 56 & 148.8 & 8 \\
\hline $\begin{array}{l}\text { Rodrigues-Pinto } \\
\text { et al. }\end{array}$ & 2013 & SALTO & No & 119 & 119 & 66 & 53 & 55.6 & 38.6 & 1 \\
\hline \multirow[t]{2}{*}{ Choi et al. } & 2013 & Mobilty (35) & No & 32 & 32 & 21 & 11 & 63 & 53.0 & 4 \\
\hline & & HINTEGRA (32) & & 35 & 35 & 20 & 15 & 62 & 34.0 & 4 \\
\hline Kohonen et al. & 2013 & AES & No & 130 & 123 & NR & NR & 56.3 & 48.7 & 45 \\
\hline Jensen et al. & 2014 & STAR & No & 42 & 42 & 17 & 25 & 61.6 & 36.0 & 39 \\
\hline Yoon et al. & 2014 & HINTEGRA & No & 99 & 90 & NR & NR & NR & 40.8 & 9 \\
\hline \multirow[t]{2}{*}{ Gaudot et al. } & 2014 & Talaris & Yes & 33 & 32 & 17 & 15 & 64 & 22.0 & 1 \\
\hline & & SALTO & & 33 & 33 & 19 & 14 & 64 & 23.0 & 8 \\
\hline Deleu et al. & 2015 & HINTEGRA & No & 50 & 50 & 25 & 25 & 54.9 & 43.0 & 24 \\
\hline Viste et al. & 2015 & AES & No & 50 & 47 & 27 & 23 & 56 & 49.0 & 40 \\
\hline \multirow[t]{3}{*}{ Gross et al. } & 2016 & STAR (103) & No & 726 & 726 & NR & NR & NR & 35.3 & 2 \\
\hline & & INBONE (293) & & & & & & & & 8 \\
\hline & & Salto Talaris (328) & & & & & & & & 21 \\
\hline \multirow[t]{5}{*}{ Singh et al. } & 2016 & SALTO (37) & No & 71 & 71 & 40 & 31 & 58 & 74.0 & 21 \\
\hline & & STAR (25) & & & & & & & & 7 \\
\hline & & HINTEGRA (5) & & & & & & & & 2 \\
\hline & & TARIC (2) & & & & & & & & 1 \\
\hline & & Others (2) & & & & & & & & 0 \\
\hline Kirkhoff et al. & 2016 & STAR & No & 134 & 124 & NR & NR & NR & NR & 61 \\
\hline
\end{tabular}

Table 3

Details of the prosthesis included in the study, distribution per number of papers and total number of implants studied.

\begin{tabular}{|c|c|c|c|c|c|c|c|}
\hline Prosthesis & Designer(s)/origin & Materials & Constrained & $\begin{array}{l}\text { No. of } \\
\text { components }\end{array}$ & Bearing & $\begin{array}{l}\text { Papers } \\
\text { (n) }\end{array}$ & $\begin{array}{l}\text { Implants } \\
\text { (n) }\end{array}$ \\
\hline Agility $^{\mathbb{R}}$ & Alvine (Iowa,USA) & $\begin{array}{l}\text { Ti tibia and talus (first 20); Ti } \\
\text { tibia, CoCr talus }\end{array}$ & Semi- & Two & Fixed & 2 & 172 \\
\hline STAR $^{\mathbb{1}}$ & Kofoed (Denmark) & $\begin{array}{l}\text { CoCr with HA coating (double } \\
\text { since 1999) }\end{array}$ & Non- & Three & Mobile & 8 & 499 \\
\hline $\mathrm{AES}^{\mathrm{B}}$ & Asencio (Nimes, France) & $\begin{array}{l}\text { CoCr with HA coating/Ti-HA } \\
\text { since } 2004\end{array}$ & Non- & Three & Mobile & 3 & 218 \\
\hline Mobility $^{\mathbb{B}}$ & $\begin{array}{l}\text { Rippstein (Zurich, Switzerland), Wood (Writhington,UK), } \\
\text { Coetzee (Minnesota, USA) }\end{array}$ & Not reported & Non- & Three & Mobile & 2 & 135 \\
\hline SALTO $^{\mathbb{R}}$ & Bonnin (Lyon, France) & CoCr with dual Ti-HA coating & Non- & Three & Mobile & 4 & 287 \\
\hline HINTEGRA ${ }^{\circledR}$ & Hintermann (Basel, Switzerland) & $\mathrm{CoCr}$ with dual Ti-HA coating & Non- & Three & Mobile & 4 & 186 \\
\hline $\mathrm{BOX}^{\mathrm{R}}$ & Rizzoli Institute (Bologna, Italy), O'Connor (Oxford, UK) & Not reported & Non- & Three & Mobile & 1 & 62 \\
\hline $\begin{array}{l}\text { Salto } \\
\quad \text { Talaris }^{\circledR}\end{array}$ & Bonnin (Lyon, France) & Ti coating & Semi- & Two & Fixed & 2 & 361 \\
\hline INBONE $^{\mathbb{R}}$ & Riley (USA) & Ti tibia, $\mathrm{CoCr}$ talus & Non- & Two & Fixed & 1 & 293 \\
\hline TARIC $^{\circledR}$ & Schill, Rehart, Fink (Germany) & $\begin{array}{l}\text { Tibia and talus: Ti coating; HA } \\
\text { coating optional }\end{array}$ & Non- & Three & Mobile & 1 & 2 \\
\hline
\end{tabular}

Ti - titanium; CoCr - cromium/cobalt; HA - hidroxyapatite.

"well-circumscribed peri-prosthetic area of lucency", "radiolucent area greater than $2 \mathrm{~mm}$ " and "demarcated hypodense zone" were the terms applied in the selected studies. Furthermore, Knecht et al. [3] distinguished two types of osteolysis: "mechanical" osteolysis, attributed to a stress shielding phenomena, characteristic of small non-progressive cysts with an early onset, and "ballooning/expansile" osteolysis due to a chemical phenomena related to wear particles, leading to late onset large progressive lesions.

Of the 2430 ankles included, 430 (17.7\%) were diagnosed with one or more peri-prosthetic bone cysts. A comparison between the total number of each type of implant and the number of cysts reported is displayed on Fig. 3.

\subsection{Location and size of cysts}

Every lesion considered to this review was defined as having a dimension of at least $2 \mathrm{~mm}$ on plain radiographs. Whenever cysts were classified by size and location, some authors refer to Besse et al. [4] 10 zones joint division and size classification (Fig. 4), others used their own protocols or simply located them according to the affected bone. Therefore, fourteen studies discriminated the 


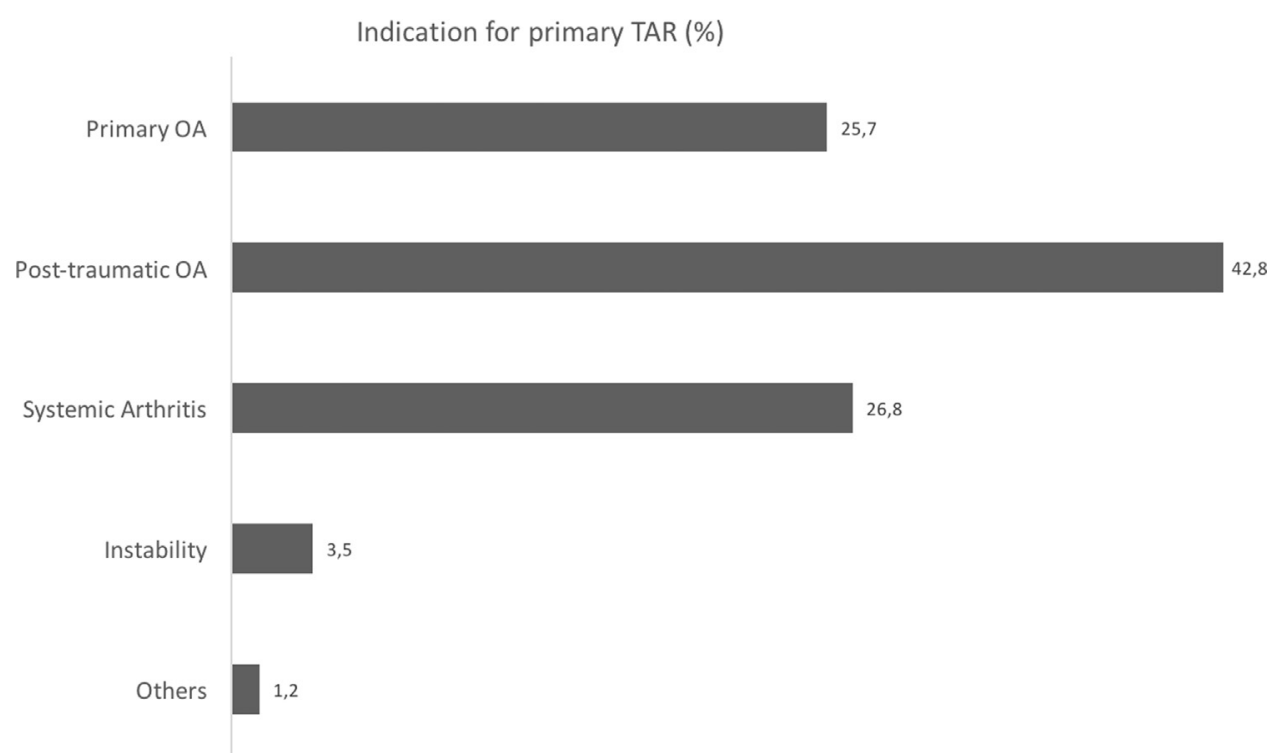

Fig. 2. Primary indication for total ankle replacement (\%) (OA, osteoarthritis).

number of cysts per location, with more lesions diagnosed in the tibia $(n=387)$ compared to the talus $(n=260)$ and few lesions detected on the fibula $(n=15)$. These differences were less evident when CT was additionally used for diagnosis [25,30], specifically because of more talar lesions being detected with this method. Zones 1, 2, 6 and 7 in the tibia and zone 9 in the talus were the most implicated areas. In the two articles that studied the results of Agility ${ }^{\circledR}$ TAR $[3,14]$, the preferential location for cystic lesions was the medial aspect of the lateral malleolus and the fusion interface of the distal tibio-fibular syndesmosis, a specific detail of this prosthesis technique. In general, the surface area of cysts was larger on CT with average cyst dimensions between $38 \mathrm{~mm}^{2}$ and

\section{Distribution of TARs and TARs with cysts by type of implant}

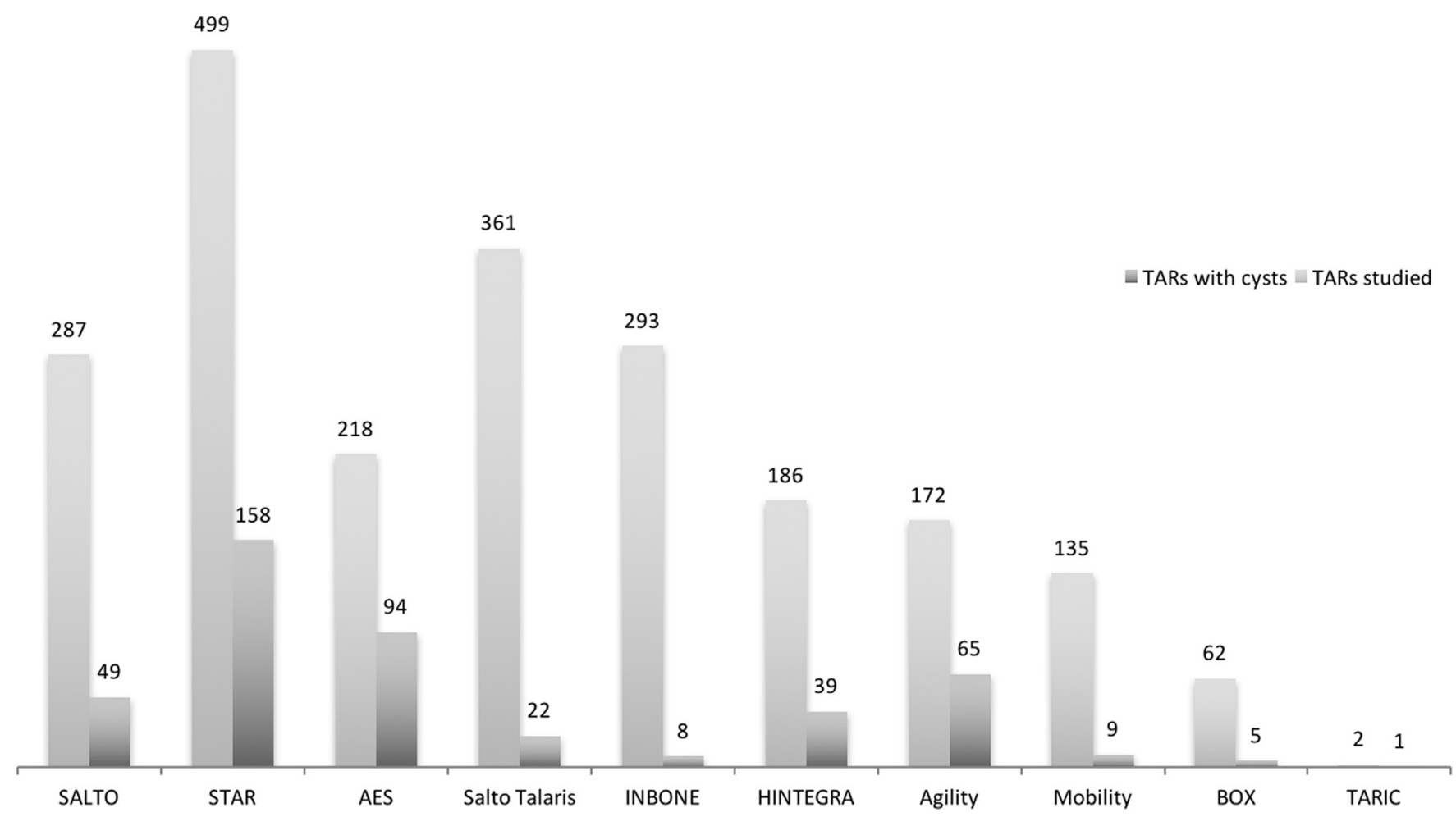

Fig. 3. Distribution of TARs (total ankle replacements) and TARs with cysts by type of implant. 


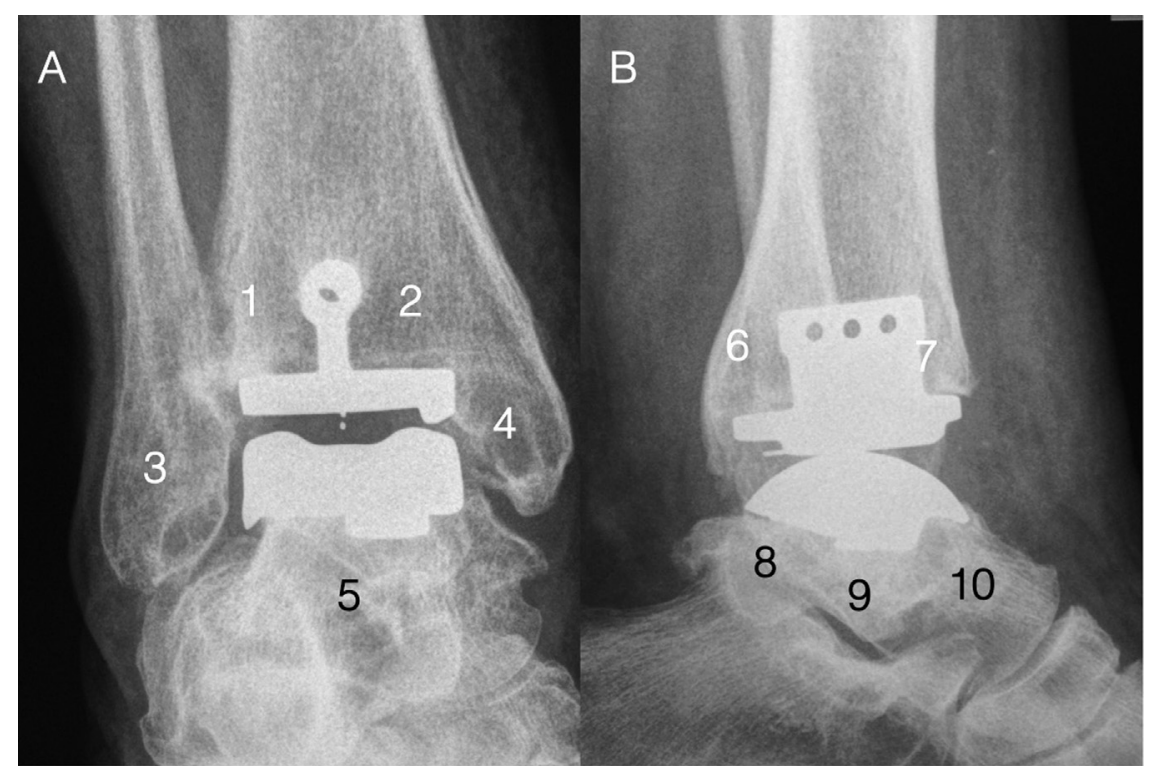

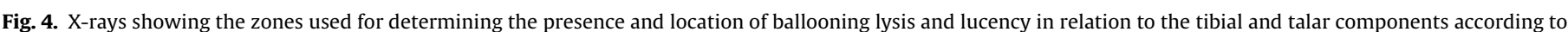

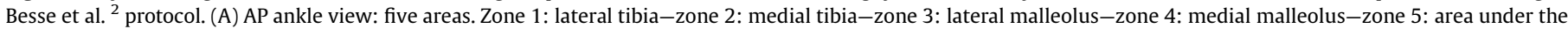

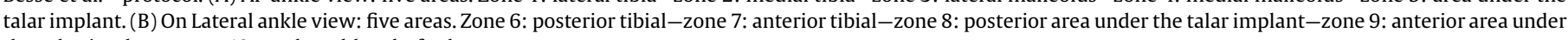
the talar implant-zone 10: neck and head of talus.

$1334 \mathrm{~mm}^{2}$ [29,30]. In one study [20] AES $^{\circledR}$ dual coated (Ti-HA) prosthesis showed more large "cyst-like osteolysis" when compared to single HA-coated implants, with average size of $180 \mathrm{~mm}^{2}$ for dual-coated and $97 \mathrm{~mm}^{2}$ for single-coated. Two examples of periprosthetic ankle cysts, from our senior author series of TARs, are illustrated in Fig. 5A and B.

\subsection{Onset and progression of cysts}

Timing of diagnosis of the first osteolytic lesions was reported in 5 studies [3,23,25,27,29], ranging from 6 to 89 months postoperatively. Again Knecht et al. [3], distinguished postoperative, mechanical stress-shielding lysis, related to non-union of the syndesmosis, from expansile lytic defects appearing at approximately 3 years after surgery, due to the presence of wear particles.
Yoon et al. [27] classified the ankles as early-onset or late-onset, based on whether the time of osteolysis detection was earlier or later than 1 year after TAR, and found a significant difference in the progression of the lesions $(P<.001)$. Half of the late-onset lesions showed continuous progression against only $9.5 \%$ in the earlyonset group.

\subsection{Cyst aetiology}

There are several proposed theories for the aetiology of the peri-prosthetic lesions. Table 4 resumes the hypothesis provided by each author. The most accepted explanation is bone lysis triggered by a foreign-body inflammatory reaction to wear particles, usually produced by shear stress. These wear debris can develop from three sources: polyethylene, metal and

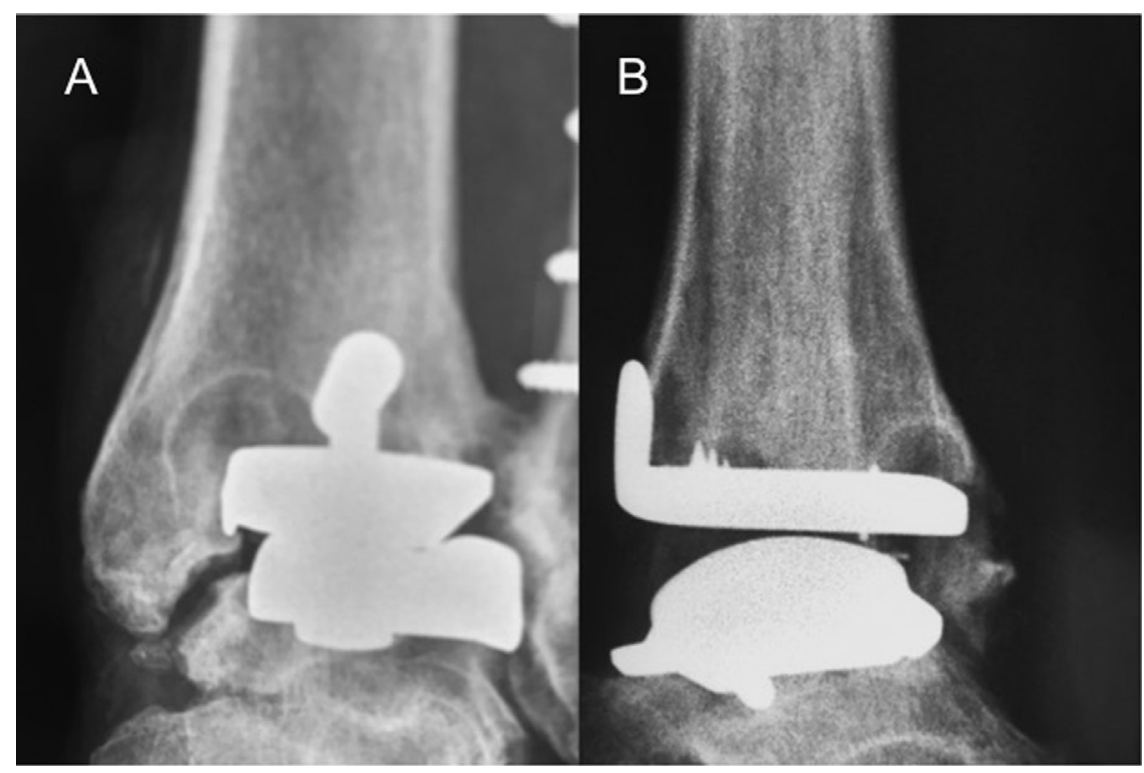

Fig. 5. (A) AP ankle view: periprosthetic zone 2 cyst. (B) Lateral ankle view: periprosthetic zone 6 cyst. 
Table 4

Summary of aetiology theories (TAR, total ankle replacement; HA, hydroxyapatite).

\begin{tabular}{|c|c|}
\hline Etiology & References \\
\hline $\begin{array}{l}\text { Non-union of the distal tibio-fibular syndesmosis (Agility }{ }^{\mathbb{B}} \text { ) produces high interfacial shear stresses between the implant and the residual } \\
\text { lateral malleolus, resulting in early post-operative balloning osteolysis. }\end{array}$ & Knecht et al. \\
\hline Inflammatory/foreign body response to generation of wear particles (polyethylene, metal, HA) & $\begin{array}{l}\text { Kokkonen et al.; Bonnin } \\
\text { et al.; }\end{array}$ \\
\hline $\begin{array}{l}\text { Compared to hip and knee replacement, TAR is more operator-dependent, with a greater risk of positioning error and consequently more } \\
\text { shear stress }\end{array}$ & Rodriguez et al. \\
\hline Third-body wear due to HA coating & Koivu et al.; Singh et al. \\
\hline $\begin{array}{l}\text { A saw is used to cut a window in the anterior tibia to admit the stem of the tibial component (Mobility }{ }^{\mathbb{R}} \text { ) and the resected portion is replaced } \\
\text { with a free bone graft. Some bone resorption is to be expected at the distal end of the graft. }\end{array}$ & Wood et al. \\
\hline $\begin{array}{l}\text { Effective joint space concept - cysts develop in periprosthetic regions that are accessible to joint fluid and thus accessible to particulate } \\
\text { debris }\end{array}$ & Bonnin et al. \\
\hline $\begin{array}{l}\text { Increased fluid pressure and micromotion prior to bone ingrowth in the bone-implant interfaces, access channels of holes in the implants } \\
\text { and screws, may play a role in the early development of osteolysis (VS host response to debris - late osteolysis). }\end{array}$ & Yoon et al. \\
\hline
\end{tabular}

hydroxyapatite. Reasons for increased wear are multifactorial depending on surgical technique, implant design, patient factors and material composition. Table 5 presents the results obtained by comparing the number of cases with cysts and revisions with the type of implant (non-anatomic vs. anatomic), type of coating, type of bearing, type of constraining and presence of a tibial stem. A statistically significant difference $(P<.001)$ was found between the type of implant, type of coating, type of bearing and presence of tibial stem, by order of association strength. More cysts are related to non-anatomic, HA-coated, mobile bearing and non tibialstemmed implants. No significant difference existed between the type of constraining and the presence of cysts $(P>.05)$.

\subsection{Revisions due to the presence of peri-prosthetic cysts}

In 12 studies there are descriptions of revision procedures, due to complications related to the presence of bone cysts, with a total of 97 procedures. Table 6 summarizes the number of revisions and revision technique in each cohort. By far, curettage and bone grafting, usually accompanied by polyethylene inlay exchange, was the most frequent technique (84 in 97 revisions). Indications for bone grafting of osteolytic defects were rapid progression of osteolysis, massive osteolysis that might lead to loosening of implants and when osteolysis accounted for more than one-third of the bone-implant interface [27]. Eight patients were treated

Table 5

Variable meta-analysis.

\begin{tabular}{|c|c|c|c|c|c|}
\hline & \multirow[t]{2}{*}{ TARs } & \multicolumn{2}{|c|}{ Cases with cysts } & \multirow[t]{2}{*}{$\mathrm{X}^{2}$} & \multirow[t]{2}{*}{$\mathrm{p}$} \\
\hline & & $\mathrm{n}$ & $\%$ & & \\
\hline \multicolumn{6}{|l|}{ Type of implant ${ }^{\mathrm{a}}$} \\
\hline Non-anatomic & 1066 & 322 & 30.2 & 172.993 & $<.001$ \\
\hline Anatomic & 1362 & 127 & 9.3 & & \\
\hline \multicolumn{6}{|l|}{ Type of coating ${ }^{\mathrm{b}}$} \\
\hline With HA & 1272 & 341 & 26.8 & 87.057 & $<.001$ \\
\hline Without HA & 958 & 104 & 10.8 & & \\
\hline \multicolumn{6}{|l|}{ Type of bearing } \\
\hline Fixed & 826 & 95 & 11.5 & 40.837 & $<.001$ \\
\hline Mobile & 1604 & 355 & 22.1 & & \\
\hline \multicolumn{6}{|c|}{ Type of constraining } \\
\hline Unconstrained & 1861 & 342 & 18.3 & 0.105 & .746 \\
\hline Semi-constrained & 569 & 108 & 19.0 & & \\
\hline \multicolumn{6}{|l|}{ Tibial stem ${ }^{a}$} \\
\hline Yes & 1291 & 182 & 14.1 & 35.329 & $<.001$ \\
\hline No & 1137 & 267 & 23.5 & & \\
\hline
\end{tabular}

a Taric $^{\mathbb{B}}$ excluded for insufficient data.

b BOX $^{\mathbb{R}}$ excluded for insufficient data. initially with implant removal and arthrodesis and 7 other cases required fusion or implant revision after cyst recurrence. Implant stability during revision was registered in 6 studies. In most cases both implants remained stable despite the presence of osteolytic lesions. Six cases of loosened implants, mainly due to talar subsidence, required prosthesis removal and arthrodesis or component revision. In one study [21], ballooning osteolysis was the only type associated with loosening and failure of the prosthesis, when compared to mechanical osteolysis.

Five articles presented the histologic results of specimens collected after curettage of the cystic bone lesions, during revision $[19,20,27,31,32]$. Two of these studies mention the specific stains used for fixation of the samples, namely HE [27], oil-red O [27] and Von Kossa [32]. In one study no further information was retrieved from the biopsies performed [20]. In a clinical cohort of 33 cases of bone cyst revision [31], the most common pathology finding was polyethylene debris in 7 patients (26.9\%), the next most common pathology identified was chronic inflammation in 6 patients (23.1\%), followed by calcium pyrophosphate dehydrate (CPPD) crystal deposition (15.3\%), unspecified foreign body reaction (11.5\%), ganglion cyst (11.5\%), metal histiocytosis (7.7\%) and granulomatous reaction (3.8\%). In Singh et al. study [32], histomorphometric, immunohistochemical, and elemental analysis of osteolytic tissues was performed and the results compared with a control group undergoing primary TAR (no osteolytic cystic lesions). Immunohistochemistry demonstrated that osteolytic tissues showed a higher expression of lymphocytes, CD3-, CD11c-, CD20-, and CD68-positive cells in a diffuse pattern compared to non-osteolytic tissues. Elemental analysis of periprosthetic tissues showed overall elevated levels of cobalt, chrome, titanium, iron, calcium, nickel and molybdenum in patients with periprosthetic cysts compared to patients without ballooning osteolysis, but the differences were significant only for calcium and iron. Additionally, the odds of having ballooning osteolysis were 297 times higher in patients with calcium levels superior to $0.5 \mathrm{mg} /$ $\mathrm{g}$ in periprosthetic tissue than in patients with calcium levels of $0.5 \mathrm{mg} / \mathrm{g}$ or less (95\% CI: 32-2798; $P<.001$ ). The remaining studies described numerous polyethylene or metallic particles surrounded by a foreign body inflammatory reaction rich in macrophages and histiocytes [19,27].

\section{Discussion}

Presently, periprosthetic cystic osteolysis is a known and recognized finding after TAR. In our review of 2430 ankles we found 430 cases of one or more periprosthetic cysts. Negative consequences for implant survival, related to mechanical instability, tibial and talar microfractures and ultimately talar component collapse, are now well established. Therefore, increasing interest in 
Table 6

Number of revisions and techniques.

\begin{tabular}{|c|c|c|c|c|}
\hline Study & Prosthesis & $\begin{array}{l}\text { Revisions due } \\
\text { to cysts }\end{array}$ & Revision technique & $\begin{array}{l}\text { Implants stable during } \\
\text { revision }\end{array}$ \\
\hline Knecht et al. & Agility & 5 & Curettage and bone-grafting of medial malleolus and inlay exchange (1) & Yes \\
\hline Kopp et al. & Agility & 0 & - & - \\
\hline Wood et al. & STAR & 1 & Bone-grafting & Yes \\
\hline Schutte et al. & STAR & NR & $\mathrm{NR}$ & NR \\
\hline Wood et al. & Mobility & 1 & Autogenous bone grafting & Yes \\
\hline Bonnin et al. & SALTO & 8 & Curettage, autogenous bone grafting and inlay exchange & NR \\
\hline $\begin{array}{l}\text { Kokkonen } \\
\text { et al. }\end{array}$ & AES & NR & Allogenic bone grafting and inlay exchange & NR \\
\hline Mann et al. & STAR & 6 & $\begin{array}{l}\text { Bone grafting (2); bone grafting and revision of at least one of the components ( } 2 \text { ); implant removal } \\
\text { and fusion ( } 2 \text { ) }\end{array}$ & Yes (2) \\
\hline Bianchi et al. & BOX & 1 & Filling with cement & NR \\
\hline Brunner et al. & STAR & 5 & Revision of the components & NR \\
\hline $\begin{array}{l}\text { Rodrigues- } \\
\text { Pinto et al. }\end{array}$ & SALTO & 1 & Surgical debridement, curettage and autogenous bone grafting & NR \\
\hline \multirow[t]{2}{*}{ Choi et al. } & HINTEGRA & 1 & Autogenous bone grafting & NR \\
\hline & Mobility & 0 & - & - \\
\hline Kohonen et al. & AES & NR & NR & NR \\
\hline Jensen et al. & STAR & NR & NR & NR \\
\hline Yoon et al. & HINTEGRA & 9 & Autogenous bone grafting + inlay exchange (8); arthrodesis with retrograde nail (1) & Yes (8) No (1) \\
\hline Gaudot et al. & $\begin{array}{l}\text { Salto } \\
\text { Talaris/ } \\
\text { SALTO }\end{array}$ & 0 & - & - \\
\hline Deleu et al. & HINTEGRA & 0 & & - \\
\hline Viste et al. & AES & 19 & $\begin{array}{l}\text { Implant removal and arthrodesis (5); curettage and grafting + inlay exchange (14) ( } 3 \text { had to be } \\
\text { revised with arthrodesis because of cyst recurrence) }\end{array}$ & NR \\
\hline Gross et al. & Mixed study & 33 & $\begin{array}{l}\text { Cyst alo-grafting ( } 25) \text {; calcium phosphate filling (4); cement filling (3); auto-grafting ( } 1 \text { ); } 4 \text { failures } \\
\text { after cyst grafting }\end{array}$ & No (3) \\
\hline Singh et al. & Mixed study & NR & NR & NR \\
\hline Kirkhoff et al. & STAR & 7 & Debridement and bone grafting & Yes \\
\hline
\end{tabular}

its aetiology and predisposing factors has emerged from recent studies. Several hypotheses have been proposed, to explain not only the elevated rate and early onset of cysts in TARs, opposing to TKAs and THAs, but also to enlighten the possible causes of this phenomena.

For instance, compared to hip and knee replacement, TAR is more operator-dependent, with a higher risk of mal-positioning and consequently higher contact pressures and more shear stress $[4,5,34]$. Other authors believe that higher rates of osteolytic cysts in TARs are secondary to the large axial loading forces on the ankle, with relatively fewer surrounding muscles for additional support [35]. Moreover arthroplasties on the hip and knee try to cover all of the resected bony surfaces with cement or with the components itself, while in most TAR designs, the subchondral bone in the talar neck or on both medial and lateral sides of the tibia are left uncovered and thus exposed to the intra-articular fluid. According to the effective joint space concept, such a disruption could eventually lead to fluid circulation and cyst formation [36,37], due to the intra-articular synovial liquid that is under pressure in a much smaller joint than the hip or knee [5]. Additionally, osteolytic lesions related to access channels provided by talar and tibial screws were also described [27].

To our knowledge, based in the literature reviewed and conducted analysis, peri-prosthetic cysts after TAR might result from both mechanical and biological factors, which predispose to the formation of wear debris and bone ostolysis induced by a thirdbody inflammatory response.

Increased mechanical wear produces particulate debris, which can migrate through bony defects, over significant distances, and contaminate a large volume of periprosthetic tissues $[38,39]$. AES $^{\circledR}$ implant, known for its high revision rate due to periprosthetic osteolysis, has been the subject of most investigations regarding the histo-pathogenesis of this phenomena. Analysis of tissues collected has confirmed the presence of foreign bodies created by premature wear. Particles of polyethylene, metal and hydroxyapatite have been implicated. Still, some authors believe that size, rather than the composition of wear particles, has the biggest impact on the biological activity of the debris [40]. Recently, Cottrino et al. identified a population of foreign bodies smaller than $50 \mu \mathrm{m}$, which represent a critical size for macrophage phagocytosis and its consequent inflammatory induced reaction [39]. Numerous pro-inflammatory cytokines participate in the process in response to these particles, producing a cascade of biological reactions, mediated by the RANKL pathway, inducing osteoclastogenesis and osteolysis and inhibiting osteogenesis $[8,10,41,42]$.

Higher mechanical interfacial shearing stress, associated with more complex multidirectional motion of non-anatomic models and mobile bearing have been described $[4,28,43]$. Indeed, our analysis revealed a significant higher percentage of cysts in nonanatomic $(30.2 \%$ vs. 9.3\%, $P<.001)$ and mobile bearing models (22.1\% vs. $11.5 \%, P<.001)$ when comparing to anatomic and fixed models, respectively.

A possible explanation for this fact is also related to the size of the particles produced. Huang and his collaborators [44-47] extensively studied biomechanical and clinical aspects of both mobile and fixed bearing TKAs. According to these authors some of the theoretical advantages of mobile bearing, regarding implant wear and durability, were questionable. Although designed to provide a more conforming articulation and superior kinematics, mobile-bearing platforms were associated with a higher risk of osteolysis due to differences in wear pattern. In fixed implants, wear consists of delamination, pitting and fracture which generate larger and fewer granular particles. Mobile bearing wear patterns are adhesion and abrasion, producing smaller, granular and more reactive particles.

Tibial stem fixation has also been implicated as a source of stress rising and therefore a predisposing factor for bone osteolysis. It is a fact that the most commonly described location for periprosthetic cysts is the tibia [20,24,27-29,48,49]. However, this 
was also true for studies that only included models with no tibial stem $[27,29,49]$. Furthermore, when comparing tibial-stemmed models with non tibial-stemmed, there were less cases of cysts related to tibial-stemmed implants (14.1\% vs. $23.5 \%, P<.001)$, possibly due to implant stability issues. Nonetheless, cysts in tibialstemmed implants resulted in significant more revisions $(P=.048)$.

Regarding implant coating, in our analysis, cases where divided in two groups depending on the presence or absence of HA in its composition. The ratio of cysts associated with HA coated implants was significantly higher than with non-HA coated implants $(26.8 \%$ vs. $10.8 \%, P<.001)$. Consistently, in a recent element analysis of 71 failed TARs, Singh et al. [32] suggested that HA coating may be a contributory factor for ballooning ostolysis, since elevated calcium levels were found in samples of patients with osteolytic lesions in comparison to non-osteolytic tissues.

Finally, and regarding TARs revisions due to osteolysis and bone cysts, data in the literature is still scarce and inconsistent. In 2011, Trincat reported a series of 322 Salto TARs with 21 cases of painful evolutive cysts treated by autograft [50]. According to their results, at more than 2 years of follow-up, there was a stable AOFAS score of 79; cysts resolved in 6 patients; 11 patients showed radiological improvement and cyst size increased in 2 ( 1 of whom underwent a second graft); 2 ankles underwent arthrodesis, indicating a $19 \%$ failure rate (4/21). Gross et al. [31] also reported good results with curetage and cyst filling. In a series of 726 TARs, 33 revision procedures were performed ( 25 cyst allografts, 4 calcium phosphate filling, 3 cement filling and 1 autograft) with a success rate of $90.9 \%$ (95\% CI: 50.8, 98.7\%) at 24 months and 60.6\% (95\% CI: $25.1 \%$, $83.4 \%)$ at 48 months. Yoon et al. [27] reported no evidence of progression of osteolytic lesions after 8 revisions with bone graft treatment. On the contrary, Besse et al. [51] analysed a series of 50 TARs for which 20 revision procedures with bone cyst curettage and grafting were performed. At a mean follow-up of 32 months, $79 \%$ functional and $92 \%$ radiological failure rate was reported and $28 \%$ were converted to arthrodesis.

On our review only 12 out of 21 studies reported their rate of revision due to cysts. Further research is warranted in order to clarify on TAR failure risk and revision indications in the presence of periprosthetic osteolysis. We found a large range in the counted number of cysts within the same prosthetic types. Although there are no obvious explanations for this it is logical to assume an influence of the diagnosis, the quality of surgery, and the method of measuring the cysts. Due to the review nature of this study we could not calculate the individual weight of each of these parameters on the number of cysts diagnosed.

Although various studies have assessed the numerous etiological, clinical, radiological and histopathological aspects related to periprosthetic ankle osteolysis, this is the first systematic review conducted so far on this subject.

Our main limitation was the inconsistency of the data reported across the studies, starting with the great variability regarding imaging diagnosis methods and the definition of peri-prosthetic bone cysts. This problem had been previously addressed by Mercer et al. [52], emphasizing the importance of standardized reporting tools for TARs adverse events. Due to the progressive availability and acknowledgement of the higher sensibility of the CT for the identification of bone cysts and other peri-prosthetic complications, an increasing number of studies rely on this imaging method for the follow-up of their cases. Most of them, however, do not provide a pre-operative $\mathrm{CT}$ examination creating a bias by failing to identify possible pre-operative cystic lesions. Prospective studies using pre-operative CT scans and CT scans at follow-up could overcome this limitation.

The main conclusion of our study is that non-anatomic, mobilebearing, hydroxyapatite-coated and non tibial-stemmed total ankle replacements are positively associated with more periprosthetic bone cysts.

We hope this report provides a consistent and systematic insight on every subject related to ankle peri-prosthetic cystic osteolysis and also highlights areas of further investigation regarding this complication.

\section{Conflict of interest}

None.

\section{References}

[1] Gougoulias NE, Khanna A, Maffulli N. History and evolution in total ankle arthroplasty. Br Med Bull 2009;89:111-51, doi:http://dx.doi.org/10.1093/bmb/ ldn039.

[2] Jackson M, Singh D. Total ankle replacement. Curr Orthop 2003;17:292-8, doi: http://dx.doi.org/10.1016/S0268-0890(02)00195-0.

[3] Knecht SI, Estin M, Callaghan JJ, Zimmerman MB, Alliman KJ, Alvine FG, et al The agility total ankle arthroplasty. Seven to sixteen-year follow-up. J Bone Jt Surg Am 2004;86-A:1161-71.

[4] Besse J-L, Brito N, Lienhart C. Clinical evaluation and radiographic assessment of bone lysis of the AES total ankle replacement. Foot Ankle Int 2009;30:96475, doi:http://dx.doi.org/10.3113/FAI.2009.0964.

[5] Rodriguez D, Bevernage BD, Maldague P, Deleu PA, Tribak K, Leemrijse T. Medium term follow-up of the AES ankle prosthesis: high rate of asymptomatic osteolysis. Foot Ankle Surg 2010;16:54-60, doi:http://dx.doi. org/10.1016/j.fas.2009.05.013.

[6] Espinosa N, Walti M, Favre P, Snedeker JG. Misalignment of total ankle components can induce high joint contact pressures. J Bone Joint Surg Am 2010;92(5):1179-87, doi:http://dx.doi.org/10.2106/JBJS.I.00287.

[7] Espinosa N, Klammer G, Wirth SH. Osteolysis in total ankle replacement. Foot Ankle Clin 2017:22:267-75, doi:http://dx.doi.org/10.1016/j.fcl.2017.01.001.

[8] Besse JL. Osteolytic cysts with total ankle replacement: frequency and causes? Foot Ankle Surg 2015;21:75-6, doi:http://dx.doi.org/10.1016/j. fas.2015.03.005.

[9] van Wijngaarden R, van der Plaat L, Nieuwe Weme RA, Doets HC, Westerga J, Haverkamp D. Etiopathogenesis of osteolytic cysts associated with total ankle arthroplasty, a histological study. Foot Ankle Surg 2015;21(2):132-6, doi: http://dx.doi.org/10.1016/j.fas.2015.02.004

[10] Dalat F, Barnoud R, Fessy MH, Besse JL. Histologic study of periprosthetic osteolytic lesions after AES total ankle replacement. A 22 case series. Orthop Traumatol Surg Res 2013;9:9, doi:http://dx.doi.org/10.1016/j.otsr.2013.07.009.

[11] Gupta SK, Chu A, Ranawat AS, Slamin J, Ranawat CS. Osteolysis after total knee arthroplasty. J Arthroplasty 2007;22(6):787-99.

[12] Kobayashi A, Minoda Y, Kadoya Y, Ohashi H, Takaoka K, Saltzman CL. Ankle arthroplasties generate wear particles similar to knee arthroplasties. Clin Orthop Relat Res 2004;424:69-72, doi:http://dx.doi.org/10.1097/01. blo.0000132182.54217.da.

[13] Zaidi R, Cro S, Gurusamy K, Siva N, Macgregor A, Henricson A, et al. The outcome of total ankle replacement: a systematic review and meta-analysis. Bone Jt J 2013;95 B:1500-7, doi:http://dx.doi.org/10.1302/0301620X.95B11.31633.

[14] Kopp FJ, Patel MM, Deland JT, O'Malley MJ. Total ankle arthroplasty with the agility prosthesis: clinical and radiographic evaluation. Foot Ankle Int 2006;27:97-103, doi:http://dx.doi.org/10.1177/107110070602700205.

[15] Buechel FF, Pappas MJ, Buechel Sr. FF, Buechel Jr. FF. Twenty-year evaluation of cementless mobile-bearing total ankle replacements. Clin Orthop Relat Res 2004;424:19-26, doi:http://dx.doi.org/10.1097/01.blo.0000132243.41419.59.

[16] Wood PL, Prem H, Sutton C. Total ankle replacement: medium-term results in 200 scandinavian total ankle replacements. J Bone Jt Surg Br 2008;90:605-9, doi:http://dx.doi.org/10.1302/0301-620X.90B5.19677.

[17] Schutte BG, Louwerens JWK. Short-term results of our first 49 scandanavian total ankle replacements (STAR). Foot Ankle Int 2008;29:124-7, doi:http://dx. doi.org/10.3113/FAI.2008.0124.

[18] Bianchi A, Martinelli N, Sartorelli E, Malerba F. The Bologna-Oxford total ankle replacement: a mid-term follow-up study. J Bone Jt Surg Br 2012;94:793-8, doi:http://dx.doi.org/10.1302/0301-620X.94B6.28283.

[19] Bonnin M, Gaudot F, Laurent JR, Ellis S, Colombier JA, Judet T. The salto total ankle arthroplasty: survivorship and analysis of failures at 7 to 11 years. Clin Orthop Relat Res 2011;469:225-36, doi:http://dx.doi.org/10.1007/s11999010-1453-y.

[20] Kokkonen A, Ikävalko M, Tiihonen R, Kautiainen H, Belt EA. High rate of osteolytic lesions in medium-term followup after the AES total ankle replacement. Foot Ankle Int 2011;32:168-75, doi:http://dx.doi.org/10.3113 FAI.2011.0168

[21] Mann JA, Mann RA, Horton E. STAR ${ }^{\mathrm{TM}}$ ankle: long-term results. Foot Ankle Int 2011;32:473-84, doi:http://dx.doi.org/10.3113/FAI.2011.0473.

[22] Brunner S, Barg A, Knupp M, Zwicky L, Kapron AL, Valderrabano V, et al. The scandinavian total ankle replacement. J Bone Jt Surg Am 2013;95:711-8, doi: http://dx.doi.org/10.2106/JBJS.K.01580. 
[23] Rodrigues-Pinto R, Muras J, Martín Oliva X, Amado P. Functional results and complication analysis after total ankle replacement. Early to medium-term results from a Portuguese and Spanish prospective multicentric study. Foot Ankle Surg 2013;19:222-8, doi:http://dx.doi.org/10.1016/j.fas.2013.06.013.

[24] Choi GW, Kim HJ, Yeo ED, Song SY. Comparison of the HINTEGRA and mobility total ankle replacements: short-to intermediate-term outcomes. Bone Jt J 2013;95 B:1075-82, doi:http://dx.doi.org/10.1302/0301-620X.95B8.

[25] Kohonen I, Koivu H, Pudas T, Tiusanen H, Vahlberg T, Mattila K. Does computed tomography add information on radiographic analysis in detecting periprosthetic osteolysis after total ankle arthroplasty? Foot Ankle Int 2013;34:180-8, doi:http://dx.doi.org/10.1177/1071100712460224.

[26] Jensen J, Frøkjær J, Gerke O, Ludvigsen L, Torfing T. Evaluation of periprosthetic bone cysts in patients with a scandinavian total ankle replacement: weightbearing conventional digital radiographs versus weight-bearing multiplanar reconstructed fluoroscopic imaging. Am J Roentgenol 2014;203:863-8, doi: http://dx.doi.org/10.2214/AJR.13.11539.

[27] Yoon HS, Lee J, Choi WJ, Lee JW. Periprosthetic osteolysis after total ankle arthroplasty. Foot Ankle Int 2014;35:14-21, doi:http://dx.doi.org/10.1177/ 1071100713509247.

[28] Gaudot F, Colombier J-A, Bonnin M, Judet T. A controlled, comparative study of a fixed-bearing versus mobile-bearing ankle arthroplasty. Foot Ankle Int 2014;35:131-40, doi:http://dx.doi.org/10.1177/1071100713517094.

[29] Deleu P-A, Devos Bevernage B, Gombault V, Maldague P, Leemrijse T. Intermediate-term results of mobile-bearing total ankle replacement. Foot Ankle Int 2015;36:518-30, doi:http://dx.doi.org/10.1177/1071100714561058.

[30] Viste A, AL Zahrani N, Brito N, Lienhart C, Fessy MH, Besse JL. Periprosthetic osteolysis after AES total ankle replacement: conventional radiography versus CT-scan. Foot Ankle Surg 2015;21:164-70, doi:http://dx.doi.org/10.1016/j. fas.2014.11.002.

[31] Gross CE, Huh J, Green C, Shah S, DeOrio JK, Easley M, et al. Outcomes of bone grafting of bone cysts after total ankle arthroplasty. Foot Ankle Int 2016;37:157-64, doi:http://dx.doi.org/10.1177/1071100715609055.

[32] Singh G, Reichard T, Hameister R, Awiszus F, Schenk K, Feuerstein B, et al. Ballooning osteolysis in 71 failed total ankle arthroplasties. Acta Orthop 2016;87:401-5, doi:http://dx.doi.org/10.1080/17453674.2016.1188346.

[33] Kerkhoff YRA, Kosse NM, Metsaars WP, Louwerens JWK. Long-term functional and radiographic outcome of a mobile bearing ankle prosthesis. Foot Ankle Int 2016;37:1292-302, doi:http://dx.doi.org/10.1177/1071100716661477.

[34] Espinosa N, Walti M, Favre P, Snedeker JG. Misalignment of total ankle components can induce high joint contact pressures. J Bone Jt Surg Am 2010;92:1179-87, doi:http://dx.doi.org/10.2106/JBJS.I.00287.

[35] Lee AY, Ha AS, Petscavage JM, Chew FS. Total ankle arthroplasty: a radiographic outcome study. Am J Roentgenol 2013;200:1310-6, doi:http://dx.doi.org/ 10.2214/AJR.12.9649.

[36] Fahlgren A, Bostrom MP, Yang X, Johansson L, Edlund U, Agholme F, et al. Fluid pressure and flow as a cause of bone resorption. Acta Orthop 2010;81:508-16, doi:http://dx.doi.org/10.3109/17453674.2010.504610.

[37] Schmalzried TP, Jasty M, Harris WH. Periprosthetic bone loss in total hip arthroplasty. Polyethylene wear debris and the concept of the effective joint space. J Bone Jt Surg Am 1992;74:849-63.
[38] Harris NJ, Brooke BT, Sturdee S. A wear debris cyst following S.T.A.R. total ankle replacement-surgical management. Foot Ankle Surg 2009;15:43-5, doi:http:// dx.doi.org/10.1016/j.fas.2008.06.002.

[39] Cottrino S, Fabrègue D, Cowie AP, Besse J-L, Tadier S, Gremillard L, et al. Wear study of total ankle replacement explants by microstructural analysis. J Mech Behav Biomed Mater 2016;61:1-11, doi:http://dx.doi.org/10.1016/j. jmbbm.2015.12.035.

[40] Ollivere B, Wimhurst JA, Clark IM, Donell ST. Current concepts in osteolysis. J Bone Jt Surg Br 2012;94:10-5, doi:http://dx.doi.org/10.1302/0301620X.94B1.28047.

[41] Koivu H, MacKiewicz Z, Takakubo Y, Trokovic N, Pajarinen J, Konttinen YT. RANKL in the osteolysis of AES total ankle replacement implants. Bone 2012;51:546-52, doi:http://dx.doi.org/10.1016/j.bone.2012.05.007.

[42] Koivu H, Kohonen I, Sipola E, Alanen K, Vahlberg T, Tiusanen H. Severe periprosthetic osteolytic lesions after the ankle evolutive system total ankle replacement. J Bone Jt Surg 2009;91:907-14, doi:http://dx.doi.org/10.1302/ 0301-620X.91B7.22434.

[43] Besse J-L, Colombier J, Asencio J, Bonnin M, Gaudot F, Jarde O, et al. Total ankle arthroplasty in France. Orthop Traumatol Surg Res 2010;96:291-303, doi: http://dx.doi.org/10.1016/j.otsr.2010.03.002.

[44] Huang C-H, Liau J-J, Cheng C-K. Fixed or mobile-bearing total knee arthroplasty. J Orthop Surg Res 2007;2:1, doi:http://dx.doi.org/10.1186/ 1749-799X-2-1.

[45] Huang CH, Ho FY, Ma HM, Yang CT, Liau JJ, Kao HC, et al. Particle size and morphology of UHMWPE wear debris in failed total knee arthroplasties - a comparison between mobile bearing and fixed bearing knees. J Orthop Res 2002;20:1038-41, doi:http://dx.doi.org/10.1016/S0736-0266(02)00015-3.

[46] Huang C-H, Huang C-H, Liau J-J, Lu Y-C, Chang T-K, Cheng C-K. Specific complications of the mobile-bearing total knee prosthesis. J Long Term Eff Med Implants 2009;19:1-11.

[47] Lu Y-C, Huang C-H, Chang T-K, Ho F-Y, Cheng C-K, Huang C-H. Wear-pattern analysis in retrieved tibial inserts of mobile-bearing and fixed-bearing total knee prostheses. J Bone Jt Surg Br 2010;92:500-7, doi:http://dx.doi.org/ 10.1302/0301-620X.92B4.22560.

[48] Wood PLR, Karski MT, Watmough P. Total ankle replacement: the results of 100 mobility total ankle replacements. J Bone Jt Surg - Br 2010;92-B:958-62, doi:http://dx.doi.org/10.1302/0301-620X.92B7.23852.

[49] Kerkhoff YRA, Kosse NM, Metsaars WP, Louwerens JWK. Long-term functional and radiographic outcome of a mobile bearing ankle prosthesis. Foot Ankle Int 2016;37:1292-302, doi:http://dx.doi.org/10.1177/1071100716661477.

[50] Trincat S, Gaudot F, Lavigne F, Piriou P, Judet T. Prothèses totales de cheville et géodes: résultats d'autogreffes osseuses à plus de 2 ans. Rev Chir Orthopédique Traumatol 2011;97:S328-9, doi:http://dx.doi.org/10.1016/j.rcot.2011.08.221.

[51] Besse JL, Lienhart C, Fessy MH. Outcomes following cyst curettage and bone grafting for the management of periprosthetic cystic evolution after AES total ankle replacement. Clin Podiatr Med Surg 2013;30:157-70, doi:http://dx.doi. org/10.1016/j.cpm.2012.10.005.

[52] Mercer J, Penner M, Wing K, Younger ASE. Inconsistency in the reporting of adverse events in total ankle arthroplasty. Foot Ankle Int 2016;37:127-36. 